\title{
Las redes comerciales del libro en la colonia: «peruleros» y libreros en la Carrera de Indias (1590-1620)/
}

\author{
The Commercial Networks of the Book Trade in Spain's \\ Colonies: Peruleros and Booksellers \\ in the Carrera de Indias (1590-1620)
}

Pedro Rueda Ramírez

Universitat de Barcelona

Se analiza una muestra de envíos de libros remitidos en los barcos que realizaron la travesía atlántica a los puertos americanos. Se trata de envíos de títulos impresos europeos destinados al abastecimiento del virreinato del Perú. En este tráfico de libros jugaron un papel clave los mercaderes que compraron títulos que enviaron a particulares, mercaderes o libreros establecidos en Perú.

Palabras Clave: Comercio de libros; Libreros; Literatura del Siglo de Oro; Consumo cultural; Sevilla; Perú; Cuzco; Lima; Potosí.

This study examines a sample of book shipments sent across the Atlantic from Seville to American ports. The shipments comprised printed works from Europe destined for the Viceroyalty of Peru. In this trading activity an essential role was played by the merchants who received orders to buy specific works, which they then sent to private individuals, merchants, and booksellers established in Peru.

KEYwordS: Book trade; Booksellers; Literature of the Siglo de Oro; Cultural consumption; Seville; Peru; Cuzco; Lima; Potosí. 


\section{Encomiendas de libros del virreinato peruano}

En este artículo intentaremos demostrar el peso creciente (y en algunos casos relevante) que tuvieron algunos comerciantes del virreinato del Perú que viajaron a Sevilla con dinero y encomiendas para la compra de libros. ${ }^{1}$ Estos comerciantes contaban con plata, compraban a los libreros lotes de libros y los registraban en los navíos al regresar al Perú. Esto les convirtió en agentes activos que en algunos casos se convirtieron en piezas esenciales del entramado del circuito de distribución de impresos que favoreció el abastecimiento del mercado peruano.

La entrada en el mercado del libro de estos agentes resultó una novedad que pudo alterar el peso del grupo de libreros sevillanos, alcalaínos o medinenses en el control del mercado del libro destinado al virreinato del Perú. ${ }^{2}$ En algunos casos compraban pequeños lotes de libros, en otros remitían libros pedidos por los lectores del Perú y, en ocasiones actuaban como agentes de mercaderes o libreros peruanos que necesitan nuevos textos para abastecer los mercados regionales. Aunque también formaron compañías con los libreros sevillanos, que de este modo contaban con mercaderes conocedores de las rutas, puertos y clientelas locales. Estos encomenderos conocedores del mundo comercial del virreinato podían convertir los riesgos asociados al envío de libros en un negocio rentable, ya que en ocasiones traían dinero y listas de libros que debían conseguir, lo que revela una clientela interesada y curiosa que busca vías para abastecerse a través de la Carrera de Indias.

La diversidad de casos que veremos revela a estos mercaderes como agentes activos en el tráfico de libros, lo que permite complementar los análisis de la historiografía, que se había centrado en los libreros andaluces o castellanos. ${ }^{3} \mathrm{Al}$ ampliar a los mercaderes que viajan de Perú a Sevilla para retornar con estos encargos podemos detectar peticiones de libros realizadas desde América, mostrando un circuito menos unidireccional de lo que algunos trabajos han revelado hasta ahora. Los peruleros permiten detectar la capacidad para incidir en la compra y la elección de las obras, a través de los encargos y las listas de libros que deben comprarse en Sevilla.

1 Vila Vilar, 1991; Álvarez Nogal, 2006.

2 Rojo Vega, 1992.

3 Álvarez Márquez, 2009; Torres Pérez, 2007; Palmiste, 2005. 
Las fuentes básicas utilizadas serán las del registro de carga de los navíos a Indias del Archivo General de Indias. Ha sido posible localizar envíos de finales del siglo XVI y en mayor medida de inicios del siglo XVII, en este último caso 48 envíos con libros en los que participaron mercaderes venidos del Perú (ver apéndice 1). La ausencia de estudios de conjunto para finales del siglo XVI dificulta el estudio comparativo, pero nos hemos basado en una muestra parcial de los navíos que viajaron en las flotas de Tierra Firme que utilizamos para el estudio de los envíos de los libreros Mexía, y en nuestra tesis doctoral para detectar los navíos de Tierra Firme de 1601 a 1620 en los que hemos podido localizar envíos de peruleros. ${ }^{4} \mathrm{La}$ reconstrucción de los cargadores a Indias realizada por los estudios del comercio Atlántico ha resultado esencial para localizar a estos mercaderes, y poder contextualizar su papel en las flotas. ${ }^{5}$ Los libros formaban parte de sus negocios, pero representaban para estos mercaderes un pequeño volumen de negocio en sus actividades.

En estos documentos es posible rastrear la presencia de mercaderes «peruleros» que empezaron a intervenir en sus inicios en torno a 1590 y siguieron con una importante presencia hasta los momentos de contracción de los negocios, que algunos autores como García Fuentes sitúan en torno a 1610, con un «espectacular retroceso de la participación de los "peruleros" en la carga directa de las flotas». ${ }^{6}$ Este trasvase de actividades de intercambio a los mercaderes del Perú estuvo vinculado a la consolidación de las redes comerciales y de negocio peruanas, pero también a coyunturas de cambio en las relaciones entre las dos orillas, y se reforzarían en momentos delicados del comercio y el crédito en Sevilla a principios del siglo XVII. De hecho al cerrarse algunos bancos sevillanos por quiebras (y arruinar a numerosos cargadores a Indias) se abrieron otros bancos en Lima, que ofrecían al comercio internacional vías para obtener préstamos y mantener el flujo de metales preciosos. ${ }^{7}$ En este sentido la formación de consulados en territorio americano supondría otro importante paso en la negociación de los agentes implicados en el tráfico Atlántico. ${ }^{8}$

Lo que ahora proponemos es, por lo tanto, un estudio centrado en un conjunto de casos que muestra los inicios del comercio de libros bajo el

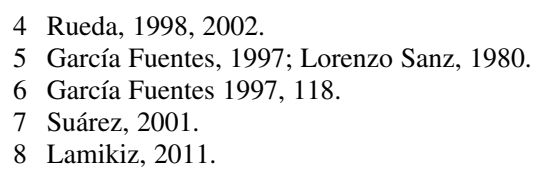


control de los mercaderes del virreinato que viajaron desde el Perú hasta Sevilla o Cádiz con la finalidad de satisfacer una demanda, y por lo tanto con una capacidad para seleccionar títulos, negociar precios y gestionar envíos, cobrando comisiones al traer la plata y al remitir los libros.

\section{Los inicios del tráfico de libros}

En 1509 un particular llevó «para las Indias» medicinas en botes y jarros de barro junto a «çinco libros de mediçina», que debieron resultarle útiles para desempeñar su oficio. ${ }^{9}$ Esta presencia temprana de libros entre las mercancías registradas en los navíos que viajaron a las nuevas tierras, apenas descubiertas por Colón diecisiete años antes, revela la temprana presencia de embarques de obras muy diversas. Ahora bien, en poco tiempo el libro se convirtió en un bien más de los enviados con cierta frecuencia a través del circuito de la Carrera de Indias. A los envíos pequeños, de lotes bien seleccionados por sus propietarios, les seguirían envíos destinados a la venta realizados por mercaderes y libreros, que empezaban a ser más relevantes desde 1540 en adelante, coincidiendo con el asentamiento de colonos europeos en los territorios conquistados, las fundaciones conventuales y la apertura de colegios y universidades. ${ }^{10}$ Este tráfico de libros a través del Atlántico puede detectarse en los territorios conquistados y pudo iniciarse, como en el caso de Santo Domingo y Honduras, con libros educativos básicos, como las cartillas para aprender a leer. En una muestra de envíos con libros de 1557 destinados al mercado centroamericano se detectaron seis envíos con cartillas (5.196 ejemplares) y doce envíos con libros que alcanzaron los 269 ejemplares. ${ }^{11}$

También tuvieron un éxito notable las menudencias impresas. Fueron consumidas en grandes cantidades toda una variada gama de «coplas», relaciones y otros textos que forman parte de lo que la crítica literaria ha etiquetado como «literatura de cordel.» Juan Alarcón de Herrera estaba en Sevilla de camino a Lima, ${ }^{12}$ y se hizo cargo de recoger en Portobelo «15 resmas de menudencias» que debían llegar a las manos del mercader Jerónimo Soto de Alvarado. El surtido comprendía 7.500 pliegos impre-

9 Archivo General de Simancas (AGS), Consejo Real, 43-5. Nao San Miguel, 83.

10 Barreto Xavier, 2011. El caso de Brasil en Abreu, 2007.

11 Rueda Ramírez, 2007.

12 Archivo General de Indias (AGI), Contratación, 5359, n. 51. 
sos remitidos enviados en 1618 con una variedad de títulos considerable que incluía, entre otros, «Carlomanos, el Cid, Marqués de Mantua, San Alexo» ${ }^{13}$ textos que se habían editado con frecuencia en las prensas españolas. Se trata de textos con una larga vida editorial y una presencia continuada en la vida cotidiana. Esto hace que resulte un reto percibir en la repetición de los formatos establecidos las «formas de ruptura, consecuencia de insatisfacciones o conflictos, manifiestos o soterrados» que en ocasiones se presenta en estas menudencias impresas. ${ }^{14}$

\section{Los cargadores a Indias}

Los cargadores a Indias y los emigrantes mantenían estrechos lazos que ayudan a entender la importante red que se construye en el mundo atlántico a pesar de las distancias y las difíciles comunicaciones. Los lazos de los peninsulares establecidos en América con actividad comercial iban más allá, como nos recuerda Altman: «los negocios, la amistad y las relaciones familiares conectaban no sólo a los emigrantes entre sí, sino también a personas que nunca salieron de España pero que tenían una relación de cualquier clase con los que sí lo hicieron», ${ }^{15}$ algo que podemos aplicar a numerosos factores e intermediarios sevillanos que fueron cargadores a Indias. Muchos de ellos establecieron sólidos lazos con los mercaderes americanos, a veces sin más contactos que las cartas, auténticos nudos que fortalecían las alianzas comerciales. Tesauro fue plenamente consciente de este cambio, en su Arte de cartas misivas afirmaba que «con el medio de las comunes postas, y cartas, que han hecho tratable el mundo, desde una a la otra remota parte». ${ }^{16}$ Estas cartas permitieron desplegar complejas estrategias comerciales haciendo «tratable el mundo» y negociable casi cualquier mercancía.

En numerosas ocasiones los acuerdos eran asentados ante los escribanos en forma de compañía comercial. Veamos un caso que permitió la llegada en 1549 de un conjunto de 79 volúmenes a Lima. Alonso Cabezas remitió un importante lote de mercancías, en el que se incluían libros, a Pero Ortiz en el puerto de Nombre de Dios y este último los remitió a Lima

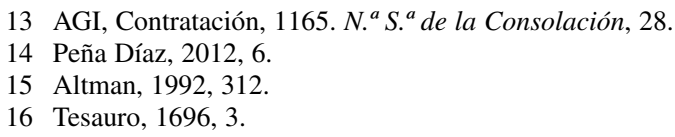


donde los vendió a Gonzalo Díaz. En el envío iban un notable número de impresos que podían resultar interesantes a los eclesiásticos, este sería el caso de las obras litúrgicas, pero también «nuebe libros de cauallerías». ${ }^{17}$ En este caso el cargador fue un mercader que activó los medios para hacer llegar el conjunto de obras a tierras peruanas, pero no fueron los únicos que intervinieron en el envío de libros. Entre los cargadores también tuvieron un peso interesante, cada vez más destacado, los eclesiásticos y oficiales reales, especialmente los que viajaron al Perú para desempeñar sus oficios. También fue esencial la demanda generada por los centros educativos, conventos e iglesias que necesitaron dotarse de libros básicos, y que contaron con el apoyo inicial de la Corona en el ejercicio de su real patronato para el envío de los textos necesarios para cumplir la misión pastoral de los religiosos en Indias.

\section{Los peruleros en el tráfico atlántico del libro}

Los mercaderes del Perú en tránsito de una orilla y otra del Atlántico llevaron consigo metales preciosos, pero también toda una gama de objetos americanos que podían interesar en Europa y no pocos encargos o regalos que debían hacer llegar a los españoles con los que negociaban o mantenían tratos y contratos de todo tipo. De este modo actuaban como mediadores económicos, pero también como intermediarios culturales que difundieron «en Occident de nouveaux symboles aux origines multiples et aux representations hybridées» en forma de obras de arte con representaciones sagradas o bien objetos cotidianos realizados con materiales americanos, por obra de mano indígena o mestiza, etc. ${ }^{18}$ La riqueza de matices en este terreno es considerable, más si cabe al adentrarnos en las redes familiares de algunos de ellos, estrechamente ligadas de un modo u otro a raíces europeas, con familiares o con relaciones de paisanaje a través de los lazos de matrimonio o de otro tipo construidos en el tránsito y el asentamiento al territorio americano de ramas de comerciantes con bifurcaciones en los territorios de la Monarquía Hispánica que negociaron con toda una amplia gama de productos culturales. ${ }^{19}$

17 Hampe Martínez, 1996, 200-202.

18 Tempere, 2007, 107.

19 Kinkead, 1984. 
La denominación peruleros para definir a estos hombres del comercio que retornan aparece ocasionalmente en la documentación. Bernardino de Morales estaba en Sevilla y presentó una petición ante la Casa de la Contratación. En ella se presentó como «perulero, residente en esta çiudad» que estaba para «volver a las provincias del Pirú» con dos esclavos que le acompañaron en su viaje y pedía, además, licencia para un cajero «que me ayude en mis cargazones. $»^{20}$ Morales había venido desde Lima y el 31 de marzo de 1621 afirmaba estar «de partida para la provincia de Tierra Firme», lo que se confirma en los documentos de poder notarial, como uno destinado al cobro a su retorno de dineros que debía entregarle Fernando de Avellaneda. ${ }^{21}$ Este perulero cargó libros en la flota de 1621 tanto para particulares como para el mercader Tomás Gutiérrez de Cisneros, una figura destacada del tráfico de libros en Lima, al que le remitió 441 ejemplares de 76 títulos distintos con «dinero que del susodicho recibió». ${ }^{22}$ Esto nos lleva al asunto del pago de las peticiones de libros que los peruleros trajeron a la Península, con esos dineros para tratar y contratar que quedaban, al menos en parte, registrados en los registros de venida de navíos. Un asunto el de los reales que pagaron los libros que nos ayudaría a conocer mejor el circuito de pago de los libros, que era clave para garantizar la buena marcha de los acuerdos comerciales. Los éxitos, y algunos fracasos, jalonaron estas aventuras comerciales, que fueron siempre arriesgadas, ya que las deudas por cobrar fueron, en numerosas ocasiones, uno de los principales problemas del tráfico de mercancías.

\section{Las rutas del libro atlántico: factores y encomenderos}

Los años de 1590 a 1600 serán analizados a través de una muestra reducida de casos ya que el siglo XVI no cuenta, por el momento, con estudios sistemáticos que permitan comparar los resultados parciales ofrecidos por diversos investigadores, ${ }^{23}$ aunque nuevas investigaciones están abriendo nuevas perspectivas de análisis y es cada vez mayor la preocupación por las redes atlánticas. ${ }^{24}$ Los cargadores presentaron las hojas de carga declarando

20 AGI, Contratación, 5396, n. 71.

21 Archivo Histórico Provincial de Sevilla (AHPS), Protocolos notariales, 3610, 141v-142v.

22 AGI, Contratación, 1171. La Candelaria, 107.

23 Torre Revello, 1940; Kügelgen, 1973.

24 Rial Costas, 2013; Raven, 2011; Palmiste, 2010. 
lo títulos que querían enviar a las Indias. Una obligación legal que el consulado de mercaderes sevillano intentó simplificar o, como en 1623, incluso eliminar. En este año escribían al rey pidiendo que «a los cargadores de las flotas que se están aprestando para Nueva España y Tierra Firme no se les pidan relaçiones juradas de sus cargazones, respecto del poco tiempo que [h] ay para poderse hacer porque por esta causa no se detengan», ${ }^{25}$ justificando en el poco tiempo disponible para formar la flota el saltarse la normativa de la Casa de la Contratación en relación a la carga de mercancías.

Estos memoriales con las mercancías declaradas debían reunirse en la Contaduría de la Casa de la Contratación y con ellos se formaban los voluminosos expedientes del registro de ida de navíos, una copia de este registro debía entregarse al maestre que iba en el navío para gestionar la entrega de las mercancías en el puerto de destino. ${ }^{26}$ Cualquier omisión o error en la copia podía dar lugar a la pérdida de las mercancías. En estos registros encontramos una nómina rica de peruleros que podemos comparar con los obtenidos por García Fuentes al rastrear su actividad en las flotas. Esto nos ha permitido comprobar el papel de estos pasajeros que retornan con miles de pesos invertidos en mercancías y libros. Gaspar de Perales trajo plata desde Lima «para emplear» a lo largo de varias flotas, entre 1589 y 1595 , y embarcó libros en 1592, únicamente una caja con obras de historia, literatura y religión, entre las que destacan las «Galateas», el «Pastor de Yberia» o la «Silva de varia lezión». ${ }^{27}$ Estos peruleros se abastecían generalmente en Sevilla, lo que resultaba un buen negocio para los libreros sevillanos. Es el caso de Jácome López, un librero que en 1592 juraba que vendió «nueve caxas y juro a Dios que fueron quatro mil reales los cuales vendí al señor Francisco Estrada Beltrán para llevar a Lima».28 Este Francisco de Estrada Beltrán fue un perulero con importantes negocios en la flota. Esta plata peruana invertida en libros fue un factor clave, ya que proporcionaba liquidez a los negocios de librería sevillana. La llegada de peruleros ofrecía unos beneficios considerables, ya que el librero no tenía que arriesgar en el negocio, aunque sus beneficios fueran menores. El librero Jácome López era uno de los que negociaba habitualmente con estos mercaderes, pero también con los sevillanos. En 1583 Alonso de Mendoza, mercader de paños, compró libros por 9.222 reales que le había encuader-

25 AGS, Consejo y Juntas de Hacienda, 592-1-3(1).

26 González Sánchez, 2004; Jacobs, 2004, 389; Rodríguez Lorenzo, 2011.

27 AGI, Contratación, 1094. N. ${ }^{a} S .^{a}$ de la Concepción, 199. García Fuentes, 1997, 103.

28 AGI, Contratación, 1094. N. ${ }^{a} S .^{a}$ de la Concepción, 330. García Fuentes, 1997, 101. 
nado López y que debían estar listos para enviar a las Indias. ${ }^{29}$ En cualquier caso, fueron varios los peruleros que acudieron a la tienda de Jácome López, como Miguel de Ochoa, que en 1594 le compró libros por valor de 1.700 reales, unos tomos que se embarcaron en siete cajas con una variedad temática y de títulos notable que veremos más adelante con detalle.

En estos casos los peruleros compraban los libros en las librerías de la ciudad o bien a otros intermediarios, en alguno de los almacenes habilitados para el tráfico o incluso entre los lotes de depósito que algunos mercaderes de libros dejaban en las tiendas sevillanas. En estos casos estos lotes podían remitirse bien a particulares que demandaban textos concretos, a otros mercaderes en Quito, Potosí o Cuzco, o a libreros limeños como Diego Méndez que declaraba ser «mercader de libros» al recibir un lote llegado desde Alcalá de Henares ${ }^{30}$ Los peruleros adquirían los libros y los enviaban respondiendo a una demanda concreta, generalmente mediante una lista de títulos que debían conseguir en Sevilla. Los libreros españoles de otras ciudades, especialmente Medina del Campo, Alcalá de Henares, Madrid, pero también de Valencia o Barcelona, aprovechaban estas oportunidades para distribuir sus libros. Desde distintas ciudades castellanas solían acudir a Sevilla coincidiendo con los momentos de preparación de las flotas, ya que resultaba una buena oportunidad para ofrecer los libros recién editados, vender las novedades traídas del extranjero y dar salida a los libros de sus stocks. ${ }^{31}$

En lo que se refiere al siglo XVII nos centraremos en los años 16011620. En concreto en el estudio de 487 registros con libros remitidos en los navíos de viaje a América, 183 envíos se registraron en los galeones de Tierra Firme. ${ }^{32}$ En estos envíos no siempre se especifican los ejemplares embarcados, y en el total de la suma del cuadro siguiente están excluidas las menudencias en el número total de ejemplares. Estos pliegos impresos se cuentan por resmas y no siempre se declaran en las listas, ya que en ocasiones no se declararon y en pocos casos se detallaba la cantidad o los títulos. En este sentido el total de ejemplares se refiere a libros, no a la amplia gama de libretes o librillos, pliegos y otros textos impresos que constituyeron, probablemente, una parte muy importante del tráfico de material impreso, ya que resultaban económicos y de más fácil venta en sectores muy amplios de la sociedad colonial.

29 Álvarez Márquez, 2007, 119.

30 Leonard, 1979, 387. El contexto de Alcalá de Henares en Martín Abad, 1997.

31 Rojo Vega, 1992; Libros y ferias, 2011.

32 Rueda Ramírez, 2005. 


\section{PEDRO RUEDA RAMÍREZ}

\begin{tabular}{|c|c|c|c|c|c|c|}
\hline$N .^{o}$ & Año & Perulero & Enviados por cuenta de & Maravedies & Títulos E & Ejemplares \\
\hline 1 & 1601 & González Refolio, Pedro & González Refolio, Pedro & 493.000 & 229 & 1.872 \\
\hline 2 & 1605 & Arias de Buiza, Rodrigo & Mexía, Hernando & 40.800 & 22 & 278 \\
\hline 3 & 1605 & Correa, Diego & Toro, Antonio de & 37.400 & 20 & 191 \\
\hline 4 & 1605 & Correa, Diego & Méndez, Antonio & 11.560 & 19 & 64 \\
\hline 5 & 1605 & Correa, Diego & Méndez, Antonio & 71.400 & 73 & 213 \\
\hline 6 & 1605 & Correa, Diego & Méndez, Antonio & 136.000 & 117 & 589 \\
\hline 7 & 1605 & Correa, Diego & Méndez, Antonio & 153.000 & 119 & 330 \\
\hline 8 & 1605 & Correa, Diego & Núñez Mexía, Juan & 136.680 & 118 & 338 \\
\hline 9 & 1605 & Correa, Diego & Fernández León, Pedro & 54.400 & 52 & 325 \\
\hline 10 & 1605 & Correa, Diego & Montoya, Juan de & 88.400 & 26 & 63 \\
\hline 11 & 1605 & Correa, Diego & González de Contreras, Pedro & 85.000 & 33 & 49 \\
\hline 12 & 1605 & Correa, Diego & Mariana, Juan de & 44.608 & 1 & 30 \\
\hline 13 & 1605 & Fernández de Quevedo, Juan & Valderrama, Fr. Pedro de & 17.136 & 1 & 35 \\
\hline 14 & 1605 & Fernández de Quevedo, Juan & Valderrama, Fr. Pedro de & 35.020 & 1 & 70 \\
\hline 15 & 1605 & González Refolio, Pedro & González Refolio, Pedro & 51.680 & 45 & 420 \\
\hline 16 & 1605 & González Refolio, Pedro & León, Francisco de & 71.400 & 44 & 136 \\
\hline 17 & 1605 & González Refolio, Pedro & González Refolio, Pedro & 42.500 & 43 & 250 \\
\hline 18 & 1605 & Munibe, Lope de & Munibe, Lope de & s.e. & 4 & 305 \\
\hline 19 & 1605 & Pamanes, Jerónimo de & Ramírez, Leonor & s.e. & 21 & 21 \\
\hline 20 & 1605 & Pamanes, Jerónimo de & León, Francisco de & s.e. & 37 & 110 \\
\hline 21 & 1605 & Pamanes, Jerónimo de & León, Francisco de & s.e. & 4 & 4 \\
\hline 22 & 1608 & Gónzalez de la Canal, Alonso & Vargas, Antonio de & 68.000 & 40 & 201 \\
\hline 23 & 1608 & Camos, Celedón de & Camos, Celedón de & 170.000 & 64 & 333 \\
\hline 24 & 1608 & Camos, Celedón de & Torre, Ana de la & 27.200 & 22 & s.e. \\
\hline 25 & 1608 & Galiano, Francisco & Galiano, Francisco & s.e. & 5 & s.e. \\
\hline 26 & 1608 & Galiano, Francisco & Cano, Francisco & 6.800 & 6 & 6 \\
\hline 27 & 1608 & Galiano, Francisco & Galiano, Francisco & s.e. & 7 & s.e. \\
\hline 28 & 1608 & Ramírez Cerrato, Juan & Cruz, Blas & 54.978 & 36 & 36 \\
\hline 29 & 1610 & Basualdo, Francisco de & Basualdo, Francisco de & 13.600 & 4 & 23 \\
\hline 30 & 1610 & Basualdo, Francisco de & Varios particulares limeños & 149.600 & 12 cajones & s s.e. \\
\hline 31 & 1610 & Pérez de Gordezuela, Juan & Pérez de Gordezuela, Juan & 76.500 & 23 & 69 \\
\hline 32 & 1610 & Arias de Buiza, Diego & Arias de Buiza, Diego & s.e. & 3 cajones & s.e. \\
\hline 33 & 1612 & Arias de Valencia, Juan & Arias de Valencia, Juan & s.e. & 3 & 3 \\
\hline 34 & 1612 & Galiano, Francisco & Núñez de Illescas, Juan & 74.800 & 102 & s.e. \\
\hline 35 & 1612 & Galiano, Francisco & Núñez de Illescas, Juan & 17.000 & 20 & s.e. \\
\hline 36 & 1612 & Galiano, Francisco & Mexía, Hernando & 37.400 & 60 & s.e. \\
\hline 37 & 1612 & Plaza, Juan de la & Galiano, Francisco & 54.000 & 13 & 148 \\
\hline 38 & 1612 & Quesada, Jácome de & Aguero, Fr. Nicolás de & 27.200 & 5 & s.e. \\
\hline 39 & 1615 & Atienza, Pedro de & Manrique, padre (S.I.) & 68.000 & 3 cajones & s.e. \\
\hline 40 & 1615 & Atienza, Pedro de & Atienza, Pedro de & s.e. & 2 cajones & s.e. \\
\hline 41 & 1615 & Atienza, Pedro de & Atienza, Pedro de & s.e. & 1 cajón & s.e. \\
\hline 42 & 1615 & Galiano, Francisco & Canseco, Juan de & s.e. & 13 & 13 \\
\hline 43 & 1615 & Galiano, Francisco & Mexía, Hernando & 122.400 & 55 & s.e. \\
\hline 44 & 1615 & Galiano, Francisco & Mexía, Hernando & 102.000 & 60 & s.e. \\
\hline 45 & 1615 & Galiano, Francisco & Elías, Fr. Juan de & 88.400 & 63 & s.e. \\
\hline 46 & 1615 & Galiano, Francisco & Lastaun, Esteban & 102.000 & 45 & s.e. \\
\hline 47 & 1615 & Galiano, Francisco & Solórzano, Juan de & 20.400 & 27 & 27 \\
\hline 48 & 1618 & Vázquez, Antolín & Soto Alvarado, Jerónimo de & 68.000 & 10 & 895 \\
\hline
\end{tabular}


En el apartado siguiente nos encargaremos con más detalle de los libros que embarcaron estos importantes cargadores, ahora apuntaremos algunos de los rasgos de estos peruleros. Francisco de Basualdo, vecino de Lima, llevó un cajón de libros con dos «quistiones regulares de fray Manuel Rodríguez; quatro santorales de Valderrama 123 parte; treçe Blosios; quatro obras de fray Luis de Granada». ${ }^{33}$ Las Obras de Ludovico Blosio eran de las más recomendadas por los autores ascéticos, y cuando se trataba de ser «amigo de leer buenos libros» era uno de los habituales, junto a Fr. Luis de Granada, tal como indicaba Jaime Cabana que intentaba guiar al lector para que sacara fruto «de la lición santa, y devota» ya que «la lición de libros profanos y lascivos es peste, y destrucción de las almas». ${ }^{34}$ Este era un lote pequeño, pero muy bien seleccionado, con rápida salida en el mercado limeño al que llegaban estos textos de manera habitual. La tónica de los envíos indica que se cargan lotes para particulares (bibliotecas viajeras o lotes bajo demanda), o bien una cuidada selección de títulos que pudieran introducirse en el mercado del Perú con facilidad.

Diego Arias de Buiza es otro de los cargadores que trafica en la Carrera al calor de los capitales indianos recibidos para negociar en Sevilla. En 1600 Arias de Buiza figuraba como residente en Sevilla en una carta de pago de 3.200 reales por asuntos comerciales. ${ }^{35} \mathrm{Al}$ poco tiempo dio el salto y en 1605 este salmantino recibía licencia para ir como pasajero a Perú. De este modo iniciaba una carrera ascendente en la que seguía los pasos de su padre, Rodrigo Arias de Buiza. Este último negociaba, con intensidad, en el trasiego de mercancías del negocio atlántico y tenía una extensa red de contactos. En 1604 entregaba en Sevilla «una fuente de plata grande labrada con la ystoria del cerro de Potosí» para que la llevaran a Salamanca. ${ }^{36}$ Diego Arias de Buiza llevó libros en dos de sus viajes a Tierra Firme. En concreto compró en casa de Hernando Mexía un lote de 24 libros jurídicos, algunos en «papel real», es decir, con amplios márgenes y de mayor calidad, lo que resultaba adecuado para incorporar anotaciones y

33 AGI, Contratación, 1156B. La Magdalena, 273.

34 Cabanas, 1689, 165.

35 AHPS, Protocolos, 12603 (1600 VI del oficio 19), s/f.

36 AHPS, Protocolos, 12630, lib. IV. AGI, Contratación, 5285, n. ${ }^{\circ} 35 ; 5317$, n. ${ }^{\circ} 2$, r. 34; 5341, n. ${ }^{\circ}$ 40. El expediente de bienes de difuntos de Rodrigo Arias de Buiza de 1617 en Contratación, 518, n. ${ }^{\circ} 1$, r. 2. García Fuentes (1997, 111-112) da cuenta de los negocios de padre e hijo entre 1595-1610. En los protocolos notariales abundan los negocios de Rodrigo Arias de Buiza, como los cien quintales de cera blanca que se obligó a entregar al mercader flamenco Francisco de Conique. AHPS, Protocolos, 12.627 . 
escolios por parte del lector. Estos libros los embarcó para «Acuña Olivera, colegial en Los Reyes», ${ }^{37}$ que podría corresponderse con Bartolomé de Acuña y Olivera, colegial en San Marcos de Lima que compareció en 1606 como testigo en una información de Bartolomé Martínez. ${ }^{38}$ Arias de Buiza continuó negociando y en 1610 envió mercancías a Lima, de donde recibió barras de plata, y declaró que iban por su cuenta y riesgo «tres caxones... con libros». ${ }^{39}$ Este mismo año consiguió el pase de la Casa de la Contratación para embarcarse con destino al Perú, acompañado de Hernando de Mesa «criado que truje de aquellas partes».40

Un factor limeño destacado fue Juan Pérez de Gordezuela. En los galeones de Juan de la Cueva de 1610 llevó mercancías procedentes «de la plata que de su cuenta truxo», una coletilla habitual que incluían los mercaderes peruanos de retorno. El lote contaba con textos de teología escolástica, sagrada escritura y devoción, en total 12 títulos y 69 ejemplares. ${ }^{41} \mathrm{La}$ selección incluía «1 Obras del pe Salmerón en 16 tomos en perg» y «1 Obras de Bañez sobre Santo Tomás en 4 tomos», que indican que el destinatario era un letrado, una biblioteca conventual o un colegio, que podían pagar un precio elevado por un lote que únicamente podía satisfacer el interés de un segmento de lectores que entendía el latín y se interesaba por las disquisiciones escolásticas.

Las excelentes relaciones comerciales que mantenía Correa en Lima facilitaron que en 11 ocasiones cargara libros en Sevilla. Su nombre aparece con frecuencia en los «registros» de carga de grandes cantidades de mercancías para su tío Antonio Correa, Juan de Lumbreras y otros comerciantes limeños. ${ }^{42}$ En 1605 cargó libros en diez ocasiones, por ejemplo, registró por cuenta y riesgo del librero Antonio de Toro y, también, del librero madrileño Juan de Montoya. Envió 8 cajones para el doctor Juan Núñez Mexía de Lima con 330 ejemplares, remitió a Pedro Fernández de León un lote de 52 títulos que sumaron 325 ejemplares y actuó de intermediario en el envío de la Historia de España que realizó su autor, el P. Juan de Mariana, remitiendo 30 ejemplares a Lima. En la mitad de los envíos, en cinco casos, los libros iban por cuenta y riesgo de Antonio Méndez, que

37 AGI, Contratación, 1145A. San Vicente, 271.

38 AGI, Patronato, 139, n. 1, r. 4.

39 AGI, Contratación, 1156B. La Magdalena, 188.

40 AGI, Contratación, 5317, n. 2, r. 34, 1.

41 AGI, Contratación, 1156B. La Magdalena, 160. García Fuentes, 1997, 119.

42 Diego Correa obtuvo licencia de pasajero en 1600. AGI, Indiferente, 2105, n. 2. Actúa, generalmente, en sociedad con su tío, enviándole grandes lotes de mercancías. García Fuentes, 1997, 112. 
recibió estas mercancías en Cartagena y Portobelo, como factor a cuyo cargo quedaba encaminarlas a Lima. En total la intervención de Correa facilitó la exportación de 2.341 ejemplares que alcanzaron un total de 859.248 maravedíes, con un valor medio de 10,8 reales por ejemplar. Es un volumen de exportación considerable, que nos da una idea aproximada del potencial de carga que podía llevar un mercader de la Carrera de Indias.

Francisco Galiano fue un viajero incansable. Este mercader cargó libros en 13 ocasiones en los años 1608, 1612 y 1615. En cada uno de estos años remitió mercancías de todo tipo, ya que fue comisionado por mercaderes limeños que le facilitaron importantes cantidades de plata para emplear, tal como revelan sus idas y venidas a través de los expedientes de pasajero a Indias. ${ }^{43}$ Uno de estos inversores fue el tesorero Francisco Cano, a su cuenta y riesgo remitió Galiano en 1608 un total de 6 títulos de libros jurídicos y litúrgicos, en concreto un breviario y un diurno. Galiano solía anotar el destinatario, dando cuenta de la persona a la que debía hacerse llegar los cajones. Al Cuzco remitió 122 títulos (en dos envíos) para el presbítero Juan Núñez de Illescas; 27 títulos los envió al prestigioso oidor Juan de Solórzano; 63 títulos fueron a manos del fraile mercedario Juan de Elías y 13 títulos para el alcalde de corte Juan de Canseco. Es un fiel reflejo del segmento de letrados consumidores de textos y dispuestos a invertir en libros. Galiano tampoco tenía problema en colaborar con libreros de la propia Carrera de Indias, como Hernando Mexía que le encargó la cargazón de dos lotes de 55 y 60 títulos en 1615, destinados a su venta en el Perú.

Ahora bien, el cuadro anterior no agota, en modo alguno, la presencia de peruleros en Sevilla cargando libros. Es tan sólo una muestra significativa de los que cargaban en grandes cantidades mercancías e incluían libros en sus actividades. Otros muchos viajeros que retornaban traían encomiendas y acudieron a los libreros sevillanos para comprar lotes. Fernán Ramírez del Molino registró en 1601 a Juan de Iria, residente en Potosí, 24 «oratorios de fray Luis, diez y seis docenas de cartillas, quatro oficios de Semana Sancta, veynte oras de latín, seis dozenas de papeles de historia». ${ }^{44}$

La red de comerciantes del virreinato peruano y el peso de sus negocios en Sevilla se redujo en los inicios del siglo XVII. Esto se refleja en las hojas de registro. En cualquier caso, como veíamos anteriormente, los comerciantes sevillanos siguieron participando ampliamente en las redes

43 AGI, Contratación, 5328, n. 28 (1612); 5347, n. 40 (1615); 5371, n. 5 (1620).

44 AGI, Contratación, 1137. San Pedro, 50 y 52. 
comerciales de abastecimiento. El cambio general del ciclo económico y las quiebras y bancarrotas de bancos en Sevilla y, en la década de los veinte en Lima, afectaron, notablemente, a todo el entramado. Algunos mercaderes que negociaron activos en la Carrera de Indias en estos años, como Ana Vernegali, tuvieron que salir en defensa de sus bienes ante las quiebras bancarias y otros diversificaron sus actividades e invirtieron en censos. ${ }^{45}$ La casuística revela la diversidad de estrategias para superar los riesgos comerciales de los años veinte y treinta en el tráfico atlántico. A partir de la década de los veinte el tráfico comercial en su conjunto entró en recesión, pero la actividad del puerto sevillano (y de la bahía gaditana) fueron claves para el tráfico de libros a lo largo de las décadas siguientes. En 1643 podemos encontrar peruleros como Lázaro Colmenero, limeño en viaje de retorno, cargando mercancías para varias personas, entre ellas el secretario de la Inquisición de Lima, y envíos en los que no especificar el destinatario, como el de «dos caxones con dos escritorios y dos caxones de libros».46

\section{Los textos literarios en circulación en la Carrera de Indias}

La diversidad de negocios que realizaron los peruleros como factores conllevó una dispersión de sus actividades. Podían cargar para particulares o encomenderos, grandes lotes o apenas unos ejemplares, sirviendo de enlace en una larga cadena que llevaba los libros a sus destinatarios en América. Ahora nos centraremos en algunas de las listas de libros embarcados pero, dado el breve espacio disponible, nos ocuparemos únicamente de las obras literarias que han despertado notable interés en los estudios de la literatura. Estos textos tuvieron una presencia limitada en los envíos, pero ofrece una panorámica interesante de la evolución del interés por la puesta en mercado de las novedades y la circulación de determinados textos (novela de caballerías, poesía épica, teatro) ${ }^{47} \mathrm{La}$ escasa presencia en relación al total del tráfico comercial del libro está en consonancia con lo

45 AGI. Contratación, 334A, n. 1, r. 12. Con los autos de bienes de su marido, Juan Francisco de Fontana. Este milanés casado con Ana Vernegali obtuvo carta de naturaleza en 1597. AGS. Registro General del Sello, III-1608.

46 AGI, Contratación, 1187. N. ${ }^{a}$ S. $^{a}$ de Altagracia, 53.

47 Pérez González, 2013. Infantes, Rueda Ramírez, 2010. El marco global de la producción de las imprentas españolas en Wilkinson, 2012, y el análisis de las imprentas en Bouza, 2004. 
que muestran los inventarios de libreros y los estudios de posesión del libro en las ciudades españolas, sirva como botón de muestra el caso de Salamanca en la que se han detectado obras de literatura moderna en un $1,6 \%$ de los libros de las bibliotecas particulares, o el de Madrid donde un análisis de 1.307 inventarios indica que tan sólo 71 tenían novelas de caballerías. ${ }^{48}$ Estas cifras deben tomarse con cautela, ante la ausencia de estudios de conjunto de las bibliotecas de las ciudades americanas, pero dan una idea de la limitada incidencia de la literatura de los autores del momento en el abanico de lecturas ofertadas a través de la Carrera de Indias.

No obstante, veremos una evolución notable de la oferta de obras de entretenimiento remitidas a Lima, y este podría ser su mayor interés, al detectar una temprana recepción de los textos y una evolución notable en los títulos que llegaron. Si consideramos que al menos una parte de los títulos revelan demandas realizadas desde Lima en el momento de entregar la plata para emplearla en Castilla, podremos detectar los intereses de las comunidades de lectura, que pedían determinados libros que respondían a necesidades del mercado limeño. Al centrar la mirada en lo que embarcan quienes iban de retorno podemos fijar la atención en libros que son tratados como mercancías, pero que están ligados a intereses concretos de lectores, libreros o mercaderes limeños. Lo que no conviene olvidar es que muchos envíos no contenían obras literarias, pero respondían a necesidades e intereses igualmente clave en los intereses de adquisición de textos. Es el caso de del doctor Francisco de León que consiguió en 1605 un lote de 4 títulos del jurisconsulto Giacomo Menochio, eran el De praesumptionibus, Sexta centuria, Consiliorum y De arbitriis judicum quaestionibus et causis, títulos altamente especializados, apreciados y comunes en las bibliotecas de juristas americanos. ${ }^{49} \mathrm{Al}$ enfocar una memoria con libros destinados a un uso personal, para una biblioteca particular, podemos detectar lecturas potenciales y evaluar el peso de este tráfico de libros en la formación de algunas colecciones peruanas. En este caso, el doctor León prefirió acudir a un perulero para conseguir estos volúmenes, probablemente con alguna indicación específica sobre su calidad ya que eran costosos. En tales peticiones se solían reclamar que fueran las mejores ediciones posibles, ya que de este modo podían contar en sus bibliotecas con las últimas adiciones e índices.

48 Rey Castelao, 2005, 128. Díez Borque, 2008.

49 AGI, Contratación, 1145A. $N^{a}{ }^{a} .^{a}$ del Rosario, 83. 
Volviendo a la literatura, resulta interesante el caso del perulero Gaspar de Perales, casado y con 44 años, que cargó en 1592 en los galeones del general Francisco Martínez de Leiva mercancías por valor de 21.385 pesos ensayados. También envió una caja de libros con una diversidad temática notable:

— Declaración del credo [Juan de Ribera]

- Galateas [Miguel de Cervantes]

— Explicación de la bula [Manuel Rodríguez]

- Diretorun curatorun [Pedro Mártir Coma]

- El pastor de ybeyria [Bernardo de la Vega].

— La sisma de ingalaterra [Pedro de Rivadeneyra]

- La istoria de yscocia [Antonio de Herrera]

- Repertorio de ychauel [Jerónimo Chaves]

- Silva de varia lizion [Pedro Mexía]

— Flosantorum de Toledo [Alonso de Villegas]

- Manual y coro de frayles franciscos

- Bonifazios

- Sumas de [Antonio de] Cordoua

- Coronicas del gran Capitán

- Hartes de Antonio [de Nebrija]

- Ystoria detiopia. ${ }^{50}$

Los 16 títulos declarados apuntan a una preferencia por obras en castellano de historia y literatura, como revela la Primera parte de la Galatea (Alcalá, 1585), pero también destacan algunos textos religiosos. La diversidad temática apunta a un envío comercial, igual que el que realizó el perulero Miguel de Ochoa en 1594. Este fue un año de menor actividad de los mercaderes peruanos, pero aún así el zaragozano Ochoa a su regreso al Perú cargó 30.062 pesos ensayados en mercancías. ${ }^{51}$ Lo interesante de uno de sus envíos, en los que actúa como factor, es la abundante literatura de entretenimiento que se llevó consigo. Esto es un claro indicador de un envío dirigido a satisfacer una clientela con intereses diversificados, y como suele ocurrir en los envíos de claro cariz comercial van mezcladas las obras literarias de géneros distintos, con un especial interés por la novela

50 AGI, Contratación, 1094. N. $^{a} S .^{a}$ de la Concepción, 199. AGI, Contratación, 5239, n. 1, r. 63. García Fuentes, 1997, 101-102.

51 AGI, Contratación, 5538, lib. 3, 221. García Fuentes, 1997, 105. 
de caballerías y la poesía. Entresacamos los títulos literarios para dar una cierta idea de la oferta puntual de 1594 que llegó a los limeños:

- Tres libros cançioneros de Petrarca.

— Un libro çien novelas [Giovanni Battista Giraldi].

- Dos libros Araucanas añadidas.

— Cinco libros Galateo español [Lucas Gracián Dantisco].

- Tres libros caualleros del Febo primera y segunda parte.

- Tres libros caualleros del Febo tercera parte.

- Tres libros espejos de caballerías.

- Tres libros Primaleon.

— Tres libros Palmerin de Oliua.

— Tres libros Trapiçonda de Reynaldos.

- Dos libros Lisuarte de Grecia.

- Un libro treçientas de Juan de Mena.

- Un libro Petrarca de habersa y prospera fortuna.

— Dos libros selvas de aventuras [Jerónimo de Contreras].

- Un libro del momo [Leon Battista Alberti].

- Cuatro libros Vernaldo del Carpio.

— Un libro pastor de Filida [Luis Gálvez de Montalvo].

- Cinco florestas españolas [Melchor de Santacruz].

- Seis obras del capitán [Francisco de] Aldana.

- Seis ratos de recreaçión [Lodovico Guicciardini].

- Quatro libros harte poética.

— Siete romançerillos. ${ }^{52}$

Juan González Moya fue otro perulero que cargó libros. En 1598 embarcó en los galeones de Sancho Pardo Osorio un total de 19.987 pesos ensayados, y en uno de sus registros declaró un importante lote de libros destinados a «Alonso Reluz mercader de la villa de Potosí», ${ }^{53}$ indicando un comercio atlántico que podía llegar a zonas de interior, tradicionalmente abastecidas desde Lima. El tráfico de libros revela, en este caso, una vía alternativa para abastecer con 488 ejemplares el mercado de Potosí con textos jurídicos y religiosos, además de obras de literatura («dos Amadís de Greçia», «una Araucana», entre otros) e historia («historia del Perú de Çarate»). La afición por las secuelas del Amadís de Gaula indica la

52 AGI, Contratación, 1106. N. ${ }^{a}$ S. ${ }^{a}$ de Begoña, 94-97.

53 AGI, Contratación, 1128. San Francisco, 153. García Fuentes, 1997, 108-109. 
continuidad de las aventuras de estos caballeros en territorio americano. En este caso se trataba de la Chronica del muy valiente y esforçado Principe y Cauallero de la ardiente espada Amadis de Grecia (quizá se envía la edición lisboeta editada por Simón López en 1596). Un fenómeno que seguirá despertando interés al trasladarse las historias a versiones especialmente elaboradas para su edición en pliegos sueltos, un fenómeno que para Burke «sugiere que se habían convertido en parte de la cultura popular», ${ }^{54}$ al menos entre los lectores peninsulares y criollos de la Colonia. Además en este caso iban declarados un lote importante de libros devotos. Declaró 192 ejemplares de «devocionarios de Fr. Luis de Granada $16^{\circ}$ tablas».

Algunos de los más suculentos negocios de venta de libros destinados a Lima estuvieron en manos de libreros, pero también participaron en las compraventas numerosos mercaderes. Este es, probablemente, el caso de Juan López de Mendoza, un perulero que llegó a cargar en estos galeones 49.625 pesos ensayados, y que registró para «Isabel de Bolonia, viuda» un impresionante lote de títulos en quince cajones. En el envío se incluyeron algunos textos literarios, un apartado pequeño del total, pero revelador de la intención de satisfacer a un público con interés por las obras de entretenimiento. En este envío de 1598 iban 10 ejemplares de la Celestina, seguidos de varios volúmenes de las diferentes partes del romancero, un ejemplar del «Amadís de Gresia» o 4 del «Espejo de cauallerias», junto a la poesía épica de la «Araucana 1, 2, $3^{\mathrm{a}}$ parte». En cualquier caso en el conjunto tuvo un peso importante las obras devotas y la poesía religiosa, con entradas como los 2 «nombres de Cristo con la perfecta casada» de Fr. Luis de León. ${ }^{55}$

Un envío ejemplar en lo que se refiere a la selección de títulos de éxito es el que realizó Lope de Munibe en 1605. Este perulero llegó a registrar en los galeones de Francisco del Corral 39.877 pesos ensayados. Entre sus diversas cargazones aparece un caso singular. Envió un lote de 4 títulos de los que declaró 305 ejemplares destinados a «Domingo de Garo vecino de la ciudad de los Reyes en el resto de su quenta». En este caso eligió «cien Astetes de oraciones», «duzientos oratorios de fray Luis de Granada», «tres Bliuias de Sisto otauo»y «dos sumas de fray Manuel Rodríguez». ${ }^{56} \mathrm{El}$ lote indica una evidente preferencia por libros de devoción

54 Burke, 2000, 179; Leonard, 1933.

55 AGI, Contratación, 1130. Santa Ana, 56.

56 AGI, Contratación, 1145A. El Espíritu Santo, 244. 
como el de Gaspar Astete, probablemente el Modo de rezar el rosario y el texto del dominico Fr. Luis de Granada, su Libro de la oración y meditación, uno de los textos religiosos consumidos con más frecuencia a un lado y otro del Atlántico. El libro fue enviado en esta flota por otros cargadores, por ejemplo, Diego González Durán, declaró 6 docenas (72 ejemplares) «de oratorios de fray Luis de Granada». ${ }^{57}$ La Biblia en latín y el tratado de casos morales de conciencia del portugués Manuel Rodríguez fueron, igualmente, bastante habituales entre los envíos de los libreros. La selección de estos cuatro títulos corresponde a una clara intención de colocar con relativa facilidad la mercancía en destino.

En los años que van de 1610 a 1620 se aprecia una relativa caída de los negocios de los peruleros, y algún altibajo como el de la flota de 1615 en la que se redujeron a media docena los factores quiteños, aunque eso no quiere decir que no realizaran, en modo alguno, embarques de libros. De entre todos ellos queremos destacar el papel de Francisco Galiano que declaró 12.355 pesos ensayados en esta flota cuando se disponía a regresar con sus criados Juan Ramón y Jerónimo López..$^{58}$ Galiano registró dos cargamentos de libros que remitía a Lima el importante librero sevillano Hernando Mexía. Es interesante constatar cuáles son las obras literarias que se remitieron, sobre todo si las comparamos con las que remitió Ochoa en 1594 que hemos visto anteriormente. Las obras literarias que localizamos en ambos envíos son:

- Rimas sacras de Lope de Vega.

- Comedias de Lope de Vega sexta parte.

- Viage de los poetas al Parnaso [Miguel de Cervantes].

- Comedias de Tarraja [Francisco Agustín Tárrega].

- Romancero espiritual.

- El español Gerardo [Gonzalo de Céspedes y Meneses]. ${ }^{59}$

Es significativo el cambio total de dirección, desaparecen las novelas de caballerías, son barridos los humanistas italianos y ocupa un papel muy relevante las comedias, la novela y la poesía de autores contemporáneos al envío. Es difícil establecer una generalización a partir de casos tan puntuales, pero resulta evidente que el mercado del libro cambió, de manera

57 AGI, Contratación, 1145A. San Vicente, 127v.

58 AGI, Contratación, 5347, n. 40. García Fuentes, 1997, 122.

59 AGI, Contratación, 1162. San Francisco, 192, San Juan Bautista, 110. 
destacada, los contenidos literarios remitidos a Indias. En este ámbito específico de la literatura de entretenimiento la transformación de la oferta se aprecia de una manera clara. En cierto modo coincide con las voces de los moralistas en los púlpitos y el discurso religioso sobre los daños de la «lección de libros malos», que llevó a la Junta de Reformación a tomar medidas, como fue el no conceder licencias para publicar novelas entre 1625 y $1635 .{ }^{60}$ El elaborado panegírico de los buenos libros contaba con su contrapeso en la descarga de una cascada de argumentos contra los libros de caballería y las novelas, pero no conviene olvidar el ataque a los poetas «gentiles», considerados por el jesuita Juan Sebastián, procurador de la orden en el Perú, como especialmente malos «porque con la suavidad y dulçura, se hacen mucho más perjudiciales». ${ }^{61}$ El clima crítico del estamento eclesiástico contra estas lecturas literarias no resultó, en modo alguno, suficiente para frenar la producción o reducir el mercado, pero fue una voz constante y repetitiva que marcó la relación con los textos, ofreciendo al lector un cúmulo de motivos para desistir de sus lecturas en «libros vanos y profanos», a la par que se ofrecían alternativas aceptables desde la óptica eclesiástica. ${ }^{62}$

En realidad se dieron más cambios, probablemente a un ritmo pausado, en los envíos de menudencias impresas y en algunos libros con una larga vida editorial, y se produjo una notable transformación del mercado del libro y la oferta de literatura de entretenimiento en esta etapa de transición que estamos tratando de analizar. El caso que podría resumir estos fenómenos es el del perulero Antolín Vázquez, que en 1618 remitió a Jerónimo Soto Alvarado un lote de libros interesante, por varios motivos como enseguida veremos, respondiendo muy probablemente a una demanda para activar un negocio de venta de libros que intentó contar con materiales de amplia difusión:

- 20 docenas de perfetos christianos [Juan González de Criptana] dorados y llanos.

-24 docenas de relicarios dorados y llanos.

- 24 docenas de horatorios de fr. Luis de Granada dorados y llanos.

- 2 docenas de contentus mundi en pergamino [Thomas à Kempis].

- Un doce exercicios de Esqio [Ejercicios divinos revelados a Nicolás Eschio].

60 Cayuela, 1993.

61 Sebastián, 1630, 209.

62 Palomo, 2013. 
- Un doce comedias de Lope de uega 10 parte.

- 8 ocho libros del escudero Marcos de Obregón [Vicente Espinel].

- 4 Libros del tribunal de religiosos [José de Santa María].

- 4 Libros de la conçeçion del pe Granados.

- 15 rezmas de menudençias el uiaxe de Jerusalén, espexos de uida humana, conde Fernán Gonçalez, confesonarios, calendarios, Carlomanos, el Cid, Marques de Mantua, San Alexo, St. Francisco, Santa escalera, Flores y Blancaflor, Roberto y coplas. ${ }^{63}$

En el envío se detecta la incorporación de algunas obras recién publicadas en Sevilla, en concreto, la obra de José de Santa María (O.C.D.) titulada Tribunal de religiosos (Sevilla, 1617) y el tratado de Diego Granada (S.I.) sobre la Inmaculada Concepción, con el título De Immaculata B. V. Dei Genitricis M. Conceptione (Sevilla, 1617). Al igual que los «relicarios» que podría corresponder con el Relicario del alma del capuchino Antonio de los Mártires, un pequeño libro en $8 .^{\circ}$ publicado en Madrid en 1617. Es improbable que respondieran a una petición realizada desde Lima ya que eran libros recién publicados. Es posible que responda a una petición de novedades que se sumaron al envío. El grueso en este caso fueron textos de larga vida editorial, con numerosas impresiones en el mercado y habitualmente vendidos en las librerías. Este sería el caso de los 288 ejemplares del Libro de la oración y la meditación de Fr. Luis de Granada o los 240 ejemplares del Perfecto cristiano de Juan González de Criptana. Las menudencias del envío formaban parte de un género editorialmente bien definido, que elaboraba sus propias reglas y ofrecía guiños al lector que facilitaban la identificación de estos impresos (tipos gastados, papel de poca calidad, grabaditos, etc.). Estas características las podemos encontrar en los ejemplares publicados con frecuencia en las prensas españolas $y$, muy especialmente, en algunas imprentas alcalaínas y sevillanas. Estas «resmas» suman 7.500 pliegos impresos, dando cuenta del peso tan importante que podían llegar a alcanzar al difundirse en el Perú este tipo de obras. Los peruleros seguían, de este modo, la senda de los envíos comerciales de los libreros. Un caso podría verificarlo. En 1660 el librero madrileño Gabriel de León remitió a Lima un lote importante en 46 cajones que incluía «55 docenas de comedias sueltas de todos género y tres resmas y media de coplas de todos géneros y asimismo van 200 tratados de las paces

63 AGI, Contratación, 1165. N. ${ }^{a} S .^{a}$ de la Consolación, 28. 
de Françia». ${ }^{64}$ Las 660 obras de teatro «sueltas», los 1.750 pliegos impresos y los 200 tratados (recién publicados con la nueva de la paz con Francia) formaban un núcleo esencial de los intereses de un público amplio, interesado en las novedades del teatro, las «coplas» y las noticias políticas.

En todo caso, el análisis de los peruleros es un botón de muestra del total de envíos. Los negocios que realizaron con los libreros sevillanos plantean interrogantes interesantes. En ocasiones algunos como Antonio de Toro embarcaron libros sirviéndose de peruleros, ya que de este modo lograban contar con un intermediario que conocía al dedillo el mercado limeño y podía colocar ventajosamente los libros. En 1618 el librero sevillano Antonio de Toro había adquirido un peso notable en el negocio del libro y registró directamente los envíos en los galeones de Juan Flores de Rabanal. Toro envío en 1618 un total de 2.428 ejemplares destinados a Lima y Quito. El envío que realizó a Quito permite entrever algunos detalles de su modo de proceder. El 30 de marzo de 1621 el mercader Francisco Segura, vecino de Quito, «de partida para allá en los presentes galeones», reconocía haber recibido de Antonio de Toro «treze caxones de libros de latín y romance de diferentes facultades». Segura llegó a un acuerdo de compañía con Toro en el que afirmaba:

me obligo de los vender a los mas subidos precios que pudiere y me obligo de dar y que daré quenta y rasón con pago del principal y ganansias que del costo de España montaron los dichos treze caxones de libros honze mill y seiscientos y setenta y seis reales. ${ }^{65}$

De este modo Segura debía pagar el costo de los libros que aportó Antonio de Toro, valorados en 11.676 reales, más las ganancias, aunque «por su encomienda y renta a de llevar a diez por ciento.» Este diez por ciento era el porcentaje de ganancia para Segura, que de este modo no tenía que invertir capital ni bienes, tan sólo hacerse cargo de la carga y venderla en destino. Era un trato de compañía frecuente en la Carrera de Indias, pero los peruleros como Francisco Segura llevaban a cabo otro tipo de contratos cuando traían plata para negociar y compraban las mercancías al contado. La diversidad de los contratos también proporcionaba diferentes márgenes de beneficio a los peruleros, que contaban con una gran ventaja al traer

64 Archivo Histórico Nacional (AHN), Inquisición, 5332, n. 22.

65 AHPS. Protocolos notariales, 3610, 253-254. 
dinero contante y sonante, frente al riesgo potencial de las deudas por cobrar. De hecho, Antonio de Toro intentó curarse en salud otorgando un poder para cobrar sus deudas a «don frey Alonso de Santillán de la orden de santo domingo y obispo de la ciudad de Quito» ${ }^{66}$ ya que las deudas por cobrar y los costes de la remisión de la plata de retorno en pago de libros fueron problemas constantes para los libreros españoles, que no solían tener una gran liquidez. Estos libros remitidos a Quito debieron proceder, al menos en parte, de los que solía recibir Antonio de Toro desde la corte, como los que le remitió el impresor Luis Sánchez unos años antes de este envío, en 1615, ${ }^{67}$ o los más de 5.600 reales que debía Antonio de Toro en 1617 a Alonso Pérez, ${ }^{68}$ uno de los mercaderes de libros madrileños más activos en el intercambio librario castellano. ${ }^{69}$

\section{Las rutas de circulación: el viaje al virreinato peruano}

Las rutas que seguían los peruleros para colocar la mercancía en el virreinato son conocidas a través de diversos derroteros y descripciones de viajeros, pero también los testimonios de los oficiales de la Corona y las cartas ofrecen noticias valiosas. ${ }^{70}$ Los libros siguieron los caminos de mar y tierra del resto de mercancías. El viaje por el océano Atlántico suponía un reto para un material tan frágil como el papel, sometido a cambios de temperatura en alta mar, con una humedad notable y el riesgo constante de las entradas de agua salada que podían estropear de manera irremediable los libros. Los cajones se enceraban con la finalidad de impermeabilizarlos, pero no siempre se lograba y las pérdidas por libros mojados formaron parte de las quejas, y de las anotaciones en las cuentas de los peruleros que llevaban a su cargo los cajones. Los riesgos no acababan con la llegada a los puertos de destino en las aguas del Golfo, los puertos de Nombre de Dios o Portobelo eran meras escalas y resultaba necesario descargar los bultos, llevarlos a Panamá, embarcarlos de nuevo y llevarlos al puerto del Callao, o si viajaban por la vía de Cartagena cargarlos en recuas de mulas

66 AHPS, Protocolos notariales, 3610, 139-140.

67 Archivo Histórico de Protocolos de Madrid (AHPM), 4438, 150. Antonio de Toro debía 10.500 reales a Luis Sánchez en 1615.

68 AHPM, 4624, 185. 27 de septiembre de 1617.

69 Cayuela, 2005.

70 González Sánchez, 2008; Marquéz Macías, 2010. 
para que fueran siguiendo el camino real hasta Lima. En este trasiego comercial los mercaderes panameños jugaron un papel clave. Juan de la Fuente Almonte fue uno de estos encomenderos que inició en Panamá las operaciones que le llevaron a adquirir una situación prominente en las redes comerciales del mercado peruano. En 1598 se encontraba en Panamá recibiendo unos fardos que le envió Fernando de Vallejo y que debía remitir a Perú. En ellos iban «diez docenas de cartillas a dos reales». ${ }^{71}$ El trasiego de estos fardos le proporcionaba una ganancia del $5 \% .{ }^{72}$ En cualquier caso, bien por la vía terrestre o, la más común, la marítima, los riesgos seguían siendo importantes para un bien frágil y pesado que estaba sometido a la codicia de los oficiales reales y a la vigilancia de los comisarios inquisitoriales. El cronista López de Gómara detallaba la ruta de estos frangotes y baúles con libros, ya que

Quien va al Perú ha de yr al Nombre de Dios, y de allí a Panamá por tierra dezisiete leguas que hay. En Panamá toman otros navíos y esperan tiempo: ca no se nauega siempre aquel mar del Sur. ${ }^{73}$

Las esperas en Panamá podían ser largas y las condiciones climáticas de la ciudad no favorecían la conservación de los libros, los que se habían mojado podían pudrirse fácilmente y el riesgo de que fueran devorados, literalmente, por los insectos eran algunos de los riesgos habituales. Esto ocurría con frecuencia con las telas, igualmente sometidas a las inclemencias meteorológicas y las difíciles condiciones de conservación, debido a que los almacenes estaban mal acondicionados para salvaguardar las mercancías por mucho tiempo. ${ }^{74}$ Algunos de los libros que llegaron en la flota se quedaron en Panamá, bien para solventar deudas o bien en la dinámica comercial que impregnaba la mayor parte de las actividades económicas de la ciudad. La tienda de Andrés Navarro era un lugar que almacenaba toda clase de productos adquiridos a los mercaderes de paso, y eso incluye varios libros y materiales para escribir.

- Un librito de fray Luis de Granada intitulado contentis mundi.

- Dos salvaderas e un tintero de plomo.

- Ocho artes de Antonio [de Nebrija].

71 AGI, Contratación, 1129. La Magdalena, 24v.

72 Vila Vilar y Lohmann Villena, 2003, 49.

73 López de Gómara, 1993, 98.

74 Laet, 1998, 549-554. 
— Tres memoriales de la vida cristiana [Luis de Granda].

- Dos fardos de papel con un balón dentro en ellos

- Yten tres docenas describanías sin herramientas. ${ }^{75}$

No obstante, la mayoría de los envíos siguieron su camino a Lima. En 1592 se enviaba un lote a la ciudad de Nombre de Dios «para que el que las recibiere pase a Panamá y en la mar del sur las cargue y registre consinadas a Gonzalo Fernández de Herrera en la ciudad de los Reyes van a riesgo del monasterio de la Encarnación de monjas de la dicha ciudad», unas monjas que recibían un envío muy rico que incluía, entre otras obras, «una Biblia real grande», el «teatrum orbis en romançe» y «el caballero determinado». ${ }^{76}$

En 1605 el librero y editor alcalaíno Juan de Sarria remitió 61 cajas que debía recibir en Panamá su hijo Juan de Sarria. De ellas llegaron finalmente a Lima 45, ya que «vendió en el camino y para fletes y aviamiento dellas ocho caxas», otras ocho las dejo a cargo de su primo Gregorio de la Puerta y se encontró que al atravesar el istmo panameño algunos libros «se habían moxado». ${ }^{77} \mathrm{Al}$ embarcar en Sevilla los cargadores solían repartir en más de un navío la carga, para garantizar que al menos una parte de las mercancías llegaran a destino, y de igual manera al registrarla en Panamá volvían a utilizar esta táctica. En el caso de Juan de Sarria citado remitió en dos navíos las 45 cajas que finalmente llegaron a El Callao, el puerto de atraque de los navíos de la mar del Sur, desde donde eran llevados a lomos de mula hasta Lima. En el puerto, los cajones debían ser inspeccionados, bien por los oficiales reales cuando no existía la infraestructura inquisitorial o bien por los agentes de la Inquisición, desde 1569 en adelante, con la finalidad de localizar libros prohibidos ${ }^{78}$ Los cajones ya habían pasado una primera criba de control en Sevilla o Cádiz, y en teoría debían llegar a Lima con el visto bueno y el sello de cera del Santo Oficio que se colocaba en los cajones, pero diversas circunstancias podían impedirlo. Ya vimos como Juan de Sarria necesitó abrir las cajas ya que «parece haberse mojado algunas de Puertovelo a Panamá» por lo que fue necesario «abrírselas y tornar de nuevo a hacer»..$^{79}$

75 AGI, Contratación, 214, n. 1, r. 1. 16v, 17 y 20.

76 AGI, Contratación, 1094. N. ${ }^{a}$ S. ${ }^{a}$ de la Concepción, 15.

77 Leonard, 1979, 398.

78 Guibovich Pérez, 2003, 105-107.

79 Leonard, 1979, 398. 


\section{Conclusiones}

Conviene concluir este trabajo, algo extenso ya, y no agotar a los lectores. Es difícil recapitular el papel de estos peruleros en el tráfico atlántico de libros. La pequeña muestra de finales del XVI que aquí analizamos indica algunas tendencias interesantes, mostrando su presencia en Sevilla con plata para comprar libros y su participación en el abastecimiento del mercado limeño. Esto permite considerar su papel como un elemento clave al facilitar liquidez a los negocios de los libreros sevillanos. Y ayuda a entender su activa participación en el tráfico de libros a través de Panamá. Algunos mercaderes se iniciaron en el tráfico oceánico para pasar a convertirse en encomenderos en Panamá o asentarse en Lima con la finalidad de iniciar tratos y contratos. Esto se confirma en la primera década del siglo XVII en la que juegan un papel relevante y abren puentes para la participación en este modelo de negocio a libreros como Juan de Sarria, que sigue los pasos de los peruleros y se convierte en un agente activo en Lima. En estos años que van de 1601 hasta 1609 localizamos 32 envíos de 13 cargadores distintos. Los peruleros reducen su presencia en los años de 16111620, un momento de contracción comercial de la Carrera de Indias. En estos años encontramos 16 envíos de 6 cargadores distintos. La diferencia es notable también en los totales de títulos declarados y en los ejemplares enviados, con una tendencia a la baja en los totales declarados entre 16111620, frente a la notable riqueza temática de los envíos de finales del XVI y de la primera década de la siguiente centuria.

Los peruleros fortalecieron los mecanismos de intercambio y crearon redes eficaces que sustentaron el tráfico de libros destinados al mercado americano. El mercado peruano mostraba, en este terreno, una notable iniciativa y los propios lectores interesados en completar sus bibliotecas lograron sus objetivos de abastecimiento en el mercado europeo. Como hemos visto, los peruleros cargaban para particulares limeños, potosinos o del Cuzco, actuaban como encomenderos de los libreros sevillanos como Antonio de Toro o los Mexía, y, al menos en ciertos casos, compraron lotes de libros de fácil venta para satisfacer las demandas de los mercaderes peruanos. La diversificación de sus actividades, arriesgando la plata llevada a Sevilla en libros, participando en compañías con libreros sevillanos como el caso de Francisco Segura, y sus amplísimas redes de contactos en ambas orillas les hicieron imprescindibles en el tráfico de libros en la Carrera de Indias. 
El análisis de los títulos de libros de literatura en algunos envíos también ofrece una imagen nítida de la evolución en el abastecimiento. Se detecta una paulatina desaparición de autores renacentistas, como Petrarca o Aldana, y el descenso de envíos de las novelas de caballería. Y a la par se observa la circulación de novedades editoriales de poesía épica y el romancero espiritual, las comedias o la novela picaresca. El interés por estos nuevos textos, entre los que destacan las Rimas sacras y las comedias de Lope de Vega, es otro aspecto relevante. Esta muestra permite verificar el abastecimiento a través de canales bien establecidos que facilitaron la llegada de impresos recién publicados con novedades editoriales, aunque también se observa el éxito de las menudencias impresas de larga vida editorial, que encontraron en el virreinato peruano una nueva vía de difusión.

Recibido el 24 de febrero de 2014 Aceptado el 22 de septiembre de 2014

\section{Bibliografía}

Abreu, Márcia: «Circulação de livros entre Europa e América», Polifonia, 14, Cuiabá, 2007, 161-174.

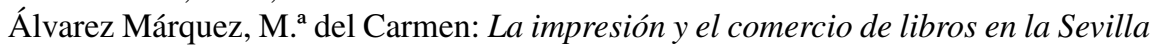
del Quinientos, Sevilla, Universidad de Sevilla, 2007.

Álvarez Márquez, M. ${ }^{\mathrm{a}}$ del Carmen: Impresores, libreros y mercaderes de libros en la Sevilla del Quinientos, Zaragoza, Libros Pórtico, 2009.

Álvarez Nogal, Carlos: «Mercados o redes de mercaderes: el funcionamiento de La feria de Portobelo», en XIV International Economic History Congress, Helsinki, 21-25 August 2006, Session 18. http://www.helsinki.fi/iehc2006/ papers1/Alvarez.pdf [Consulta: 09/05/2014].

Altman, Ida: Emigrantes y sociedad. Extremadura y América en el siglo XVI, Madrid, Alianza, 1992.

Barreto Xavier, Angela: «Les bibliothèques virtuelles et réelles des franciscains en Inde au XVIIe siècle», en Castelnau-L'Estoile, Charlotte de (ed.), Missions d'évangélisation et circulation des savoirs: XVI ${ }^{-}$-XVIII ${ }^{e}$ siècle, Madrid, Casa de Velázquez, 2011, 151-169.

Bouza, Fernando: «Los contextos materiales de la producción cultural», en Feros Carrasco, Antonio y Gelabert González, Juan Eloy (coords.), España en tiempos del Quijote, Madrid, Taurus, 2004, 309-344.

Burke, Peter: «La caballería en el Nuevo Mundo», Formas de historia cultural, Madrid: Alianza, 2000, 177-190.

Cabanas, Jaime: Espejo de amor, Gerona, Geronimo Palol, 1689. 
Cayuela, Anne: «La prosa de ficción entre 1625 y 1634: Balance de diez años sin licencias para imprimir novelas en los Reinos de Castilla», Mélanges de la Casa de Velázquez, 29-2, Madrid, 2003, 51-78.

Cayuela, Anne: Alonso Pérez de Montalbán: un librero en el Madrid de los Austrias, Madrid, Calambur, 2005.

Díez Borque, José María: «Novelas a la venta en librerías españolas del Siglo de Oro (1600-1650)», Bulletin Hispanique, 110-1, Bordeaux, 2008, 91-110.

García Fuentes, Lutgardo: Los peruleros y el comercio de Sevilla con las Indias, 1580-1630, Sevilla, Universidad de Sevilla, 1997.

González Sánchez, Carlos Alberto: «La Casa de la Contratación y la historia cultural», en Acosta Rodríguez, A.; González Rodríguez, A. L. y Vila Vilar, E. (coords.), La Casa de Contratación y la navegación entre España y las Indias, Sevilla, CSIC/Universidad de Sevilla, 2004, 543-566.

González Sánchez, Carlos Alberto: Homo viator, homo scribens: cultura gráfica, información y gobierno en la expansión atlántica (siglos XV-XVII), Madrid, Marcial Pons, 2008.

Guibovich Pérez, Pedro M.: Censura, libros e Inquisición en el Perú colonial, 15701754, Sevilla, CSIC/Universidad de Sevilla/Diputación de Sevilla, 2003.

Hampe Martínez, Teodoro: Bibliotecas privadas en el mundo colonial: la difusión de libros e ideas en el virreinato del Perú (siglos XVI-XVII), Madrid/Frankfurt, Iberoamericana/Vervuert, 1996.

Infantes, Víctor, Rueda Ramírez, Pedro: «Involuntario peregrino: la primera salida de Don Quijote hacia las Indias y de cómo arribó a ellas por el estío de 1605», en Marín Pina, M. ${ }^{a}$ del Carmen (ed.), Cervantes en el espejo del tiempo, Zaragoza/Alcalá de Henares, Prensas Universitarias de Zaragoza/Universidad de Alcalá de Henares, 2010, 173-208.

Jacobs, Auke P.: «Funcionarios con las manos en la masa. La Casa de la Contratación durante el reinado de Carlos V», en Acosta Rodríguez, A.; González Rodríguez, A. L. y Vila Vilar, E. (coords.), La Casa de la Contratación y la navegación entre España y las Indias, Sevilla, CSIC/Universidad de Sevilla, 2004, 375-500.

Kinkead, Duncan: «Juan de Luzón and the Sevillian Painting Trade with the New World in the Second Half of the Seventeenth Century», The Art Bulletin, 66-2, New York, 1984, 303-310.

Kügelgen, Helga Kropfinger-von: «Europäischer buchexport von Sevilla nach Neuspanien im Jahre 1586», en Libros europeos en la Nueva España a fines del siglo XVI: una contribución a la estratigrafía cultural, Wiesbaden, Franz Steiner Verlag, 1973, 1-105.

Laet, Joannes de: Nuevo Mundo o descripción de las Indias Occidentales, Caracas, Universidad Simón Bolívar, 1998.

Lamikiz, Xabier: «Flotistas en la Nueva España: diseminación espacial y negocios de los intermediarios del comercio transatlántico, 1670-1702», Colonial Latin American Review, 20-1, Albuquerque, 2011, 9-33. 
Leonard, Irving A.: Romances of chivalry in the Spanish indies with some «Registros» of shipments of books to the Spanish colonies, Berkeley, California, University of California Press, 1933.

Leonard, Irving A.: Los libros del conquistador, México, FCE, 1979.

Libros y ferias: el primer comercio del libro impreso. V Centenario de la Imprenta de Medina de Campo (1511-2011), [Medina del Campo], Fundación Museo de las Ferias, 2011.

López de Gómara, Francisco: Historia general de las Indias (1555), Lima, Comisión Nacional del V Centenario del Descubrimiento de América Encuentro de dos Mundos, 1993.

Lorenzo Sanz, Eufemio: Comercio de España con América en la época de Felipe II, Valladolid, Servicio de Publicaciones de la Diputación Provincial, 1980.

Márquez Macías, Rosario: «La actividad cultural en los puertos del Caribe en el siglo XVIII. El caso del comercio de libros», en Elías Caro, Jorge Enrique y Vidal Ortega, Antonino (eds.), Ciudades portuarias en la gran cuenca del Caribe: visión histórica, Barranquilla, Ediciones Uninorte, 2010, 37-73.

Martín Abad, Julián: «Alcalá de Henares, 1547-1616: Talleres de imprenta y mercaderes de libros», en Cervantes y Alcalá de Henares, Alcalá de Henares, Centro de Estudios Cervantinos, 1997, 3-9.

Palmiste, Clara: «Aspectos de la circulación de libros entre Sevilla y América (16891740)», en Gutiérrez Escudero, Antonio y Laviana Cuetos, María Luisa (coords.), Estudios sobre América, siglos XVI-XX, Sevilla, Asociación Española de Americanistas, 2005, 831-842.

Palmiste, Clara: «Los mercaderes de libros e impresores flamencos en Sevilla: organización de las redes mercantiles en Europa y América (1680-1750)», en Crespo Solana, Ana (coord.), Comunidades transnacionales: Colonias de mercaderes extranjeros en el mundo Atlántico (1500-1830), Aranjuez, Doce Calles, 2010, 251-270.

Palomo, Federico: «Cultura religiosa, comunicación y escritura en el mundo ibérico en la edad moderna», en Serrano, Eliseo (coord.), De la tierra al cielo. Líneas recientes de investigación en Historia Moderna. I Encuentro de jóvenes investigadores en historia moderna, Zaragoza, Institución Fernando el Católico, 2013, 53-88.

Peña Díaz, Manuel: «Conceptos y relecturas de lo cotidiano en la época moderna», en Peña Díaz, Manuel (ed.), La vida cotidiana en el mundo hispánico: (siglos XVI-XVIII), Madrid, Adaba, 2012, 5-20.

Pérez González, Andrea Mariel: Literatura española en la nueva España: cinco catálogos sevillanos de la década de 1680, Madrid, Universidad Complutense, 2013. Trabajo Fin de Máster. http://eprints.ucm.es/23788/

Raven, James: «Selling books across Europe, c. 1450-1800: an overview», en Feather, John (ed.), Book publishing, London and New York, Routledge, 2011, II, 347-360. 
Rey Castelao, Ofelia: «Lectores y libros en tiempos del Quijote», Pedralbes, 25, Barcelona, 2005, 103-131.

Rial Costas, Benito: «Bibliography and the History of the Printed Book in Spain: Some Insights into an Old and New Field of Study», Jaarboek voor Nederlandse boekgeschiedenis, 20, Nijmegen/Leiden, 2013, 87-97.

Rodríguez Lorenzo, Sergio Manuel: «El fletamento de mercancías en la carrera de Indias (1560-1622): introducción a su estudio», Procesos de Mercado. Revista europea de economía política, 1, Madrid, 2011, 161-207.

Rojo Vega, Anastasio: «El negocio del libro en Medina del Campo. Siglos XVI y XVII», Investigaciones Históricas, 7, Valladolid, 1988, 17-26.

Rojo Vega, Anastasio: «Los grandes libreros españoles del siglo XVI y América», Cuadernos hispanoamericanos, 500, Madrid, 1992, 115-131.

Rueda Ramírez, Pedro: Negocio e intercambio cultural: El comercio de libros con América en la Carrera de Indias ( siglo XVII), Sevilla, Universidad; Diputación de Sevilla; Escuela de Estudios Hispano-Americanos, 2005.

Rueda Ramírez, Pedro: «Las rutas del libro atlántico: libros enviados en el navío de Honduras (1557-1700)», Anuario de Estudios Americanos, 64-2, Sevilla, 2007, 61-85.

Sebastián, Juan: De el bien, excellencias y obligaciones de el estado clerical y sacerdotal, Sevilla, Matias Clavijo, 1620.

Suárez, Margarita: Desafíos transatlánticos: mercaderes, banqueros y el estado en el Perú virreinal, 1600-1700, Lima, Pontificia Universidad Católica del Perú/Instituto Riva-Agüero/Instituto Francés de Estudios Andinos/Fondo de Cultura Económica, 2001.

Tempere, Delphine: «Des marchands en mer. Voyage océanique, négoce et médiations entre l'Espagne et l'Amérique au XVIIe siècle», en Perez, Beatrice; Rose, Sonia V. \& Clément, Jean-Pierre (dir.), Des marchands entre deux mondes. Pratiques et représentations en Espagne et en Amérique (XVe-XVIII siècles), Paris, Presses de l'Université Paris Sorbonne, 2007, 103-115.

Tesauro, Emanuele: Arte de cartas misivas, Valencia, Jayme de Bordazar, 1696.

Torre Revello, José: El libro, la imprenta y el periodismo en América durante la dominación Española, Buenos Aires, Instituto de Investigaciones Históricas, 1940.

Torres Pérez, José María: «Juan Pedro Musete, mercader de libros, en Medina del Campo», Revista General de Información y Documentación, 17-1, Madrid, 2007, 81-94.

Vila Vilar, Enriqueta: Los Corzo y los Mañara: tipos y arquetipos del mercader con Indias, Sevilla, Escuela de Estudios Hispano-Americanos, 1991.

Vila Vilar, Enriqueta; Lohmann Villena, Guillermo: Familia, linajes y negocios entre Sevilla y las Indias. Los Almonte, Madrid, Fundación MAPFRE, 2003.

Wilkinson, Alexander S.: «Exploring the Print World of Early Modern Iberia», Bulletin of Spanish Studies: Hispanic Studies and Researches on Spain, Portugal and Latin America, 89-4, Glasgow, 2012, 491-506. 


\section{Apéndice}

\section{Fuentes consultadas del Registro de Ida de Navíos del Archivo General de Indias}

\begin{tabular}{|c|c|c|c|}
\hline$N .^{o}$ & Año & Perulero & Archivo General de Indias (AGI) \\
\hline 1 & 1601 & González Refolio, Pedro & AGI. Contratación, 1137. Jesús, María y José, 175. \\
\hline 2 & 1605 & Arias de Buiza, Rodrigo & AGI. Contratación, 1145B. $N^{a}{ }^{a} S^{a}$ del Rosario, $124 \mathrm{r}$. \\
\hline 3 & 1605 & Correa, Diego & AGI. Contratación, 1145A. El Espíritu Santo, 160. \\
\hline 4 & 1605 & Correa, Diego & AGI. Contratación, 1145A. El Espíritu Santo, 166. \\
\hline 5 & 1605 & Correa, Diego & AGI. Contratación, 1145A. San Vicente, 276. \\
\hline 6 & 1605 & Correa, Diego & AGI. Contratación, 1145A. $N^{a}{ }^{a}{ }^{a}{ }^{a}$ del Rosario, 100. \\
\hline 7 & 1605 & Correa, Diego & AGI. Contratación, 1145A. $N^{a}{ }^{a}{ }^{a}{ }^{a}$ del Rosario, 103. \\
\hline 8 & 1605 & Correa, Diego & AGI. Contratación, 1145A. El Espíritu Santo, 167. \\
\hline 9 & 1605 & Correa, Diego & AGI. Contratación, 1145A. San Vicente, 274. \\
\hline 10 & 1605 & Correa, Diego & AGI. Contratación, 1145A. N. $^{a}$ S. $^{a}$ del Rosario, 98. \\
\hline 11 & 1605 & Correa, Diego & AGI. Contratación, 1145A. N. ${ }^{a} S^{a}{ }^{a}$ del Rosario, 99. \\
\hline 12 & 1605 & Correa, Diego & AGI. Contratación, 1145A. N. $^{a} S^{a}{ }^{a}$ del Rosario, 106. \\
\hline 13 & 1605 & Fernández de Quevedo, Juan & AGI. Contratación, 1145A. El Espíritu Santo, 271. \\
\hline 14 & 1605 & Fernández de Quevedo, Juan & AGI. Contratación, 1145A. El Espíritu Santo, 351. \\
\hline 15 & 1605 & González Refolio, Pedro & AGI. Contratación, 1145A. El Espíritu Santo, 175. \\
\hline 16 & 1605 & González Refolio, Pedro & AGI. Contratación, 1145A. San Vicente, 321. \\
\hline 17 & 1605 & González Refolio, Pedro & AGI. Contratación, 1145B. San Pedro y $N .^{a} S .^{a}$ del Rosario, 384. \\
\hline 18 & 1605 & Munibe, Lope de & AGI. Contratación, 1145A. El Espíritu Santo, 242. \\
\hline 19 & 1605 & Pamanes, Jerónimo de & AGI. Contratación, 1145A. El Espíritu Santo, 204. \\
\hline 20 & 1605 & Pamanes, Jerónimo de & AGI. Contratación, 1145A. El Espíritu Santo, 205. \\
\hline 21 & 1605 & Pamanes, Jerónimo de & AGI. Contratación, 1145A. $N .^{a} S^{a}{ }^{a}$ del Rosario, 83. \\
\hline 22 & 1608 & Gónzalez de la Canal, Alonso & AGI. Contratación, 1151B. La Magdalena, 100. \\
\hline 23 & 1608 & Camos, Celedón de & AGI. Contratación, 1151A. Jesús, María, San Esteban, 461. \\
\hline 24 & 1608 & Camos, Celedón de & AGI. Contratación, 1151A. Jesús, María, San Esteban, 483. \\
\hline 25 & 1608 & Galiano, Francisco & AGI. Contratación, 1151A. Jesús, María, San Esteban, 131. \\
\hline 26 & 1608 & Galiano, Francisco & AGI. Contratación, 1151B. La Magdalena, 334. \\
\hline 27 & 1608 & Galiano, Francisco & AGI. Contratación, 1151B. La Magdalena, 341. \\
\hline 28 & 1608 & Ramírez Cerrato, Juan & AGI. Contratación, 1151B. San Nicolás, 169. \\
\hline 29 & 1610 & Basualdo, Francisco de & AGI. Contratación, 1156B. La Magdalena, 260. \\
\hline 30 & 1610 & Basualdo, Francisco de & AGI. Contratación, 1156B. Jesús, María, 151. \\
\hline 31 & 1610 & Pérez de Gordezuela, Juan & AGI. Contratación, 1156B. La Magdalena, 160. \\
\hline 32 & 1610 & Arias de Buiza, Diego & AGI. Contratación, 1156B. La Magdalena, 188. \\
\hline 33 & 1612 & Arias de Valencia, Juan & AGI. Contratación, 1158. Santa María de Gracia, 57. \\
\hline 34 & 1612 & Galiano, Francisco & AGI. Contratación, 1158. Santa María de Gracia, 148. \\
\hline 35 & 1612 & Galiano, Francisco & AGI. Contratación, 1158. El Buen Jesús y San Esteban, 134. \\
\hline 36 & 1612 & Galiano, Francisco & AGI. Contratación, 1158. Santa María de Gracia, 150. \\
\hline 37 & 1612 & Plaza, Juan de la & AGI. Contratación, 1158. El Buen Jesús y San Esteban, 175. \\
\hline 38 & 1612 & Quesada, Jácome de & AGI. Contratación, 1158. Santa María de Gracia, 122. \\
\hline 39 & 1615 & Atienza, Pedro de & AGI. Contratación, 1162. San Francisco, 100. \\
\hline 40 & 1615 & Atienza, Pedro de & AGI. Contratación, 1162. San Martín, 101. \\
\hline
\end{tabular}




\section{PEDRO RUEDA RAMÍREZ}

411615 Atienza, Pedro de

421615 Galiano, Francisco

$43 \quad 1615$ Galiano, Francisco

441615 Galiano, Francisco

451615 Galiano, Francisco

461615 Galiano, Francisco

471615 Galiano, Francisco

481618 Vázquez, Antolín
AGI. Contratación, 1162. San Francisco, 199.

AGI. Contratación, 1162. San Francisco, 184.

AGI. Contratación, 1162. San Francisco, 192.

AGI. Contratación, 1162. San Juan Bautista, 110.

AGI. Contratación, 1162. San Juan Bautista, 106.

AGI. Contratación, 1162. San Juan Bautista, 108.

AGI. Contratación, 1162. San Juan Bautista, 109.

AGI. Contratación, 1165. N. ${ }^{a} S{ }^{a}$ de la Consolación, 28. 